\title{
TCOM \\ Learning from the news about the consequences of climate change: an amendment of the cognitive mediation model
}

\section{Corinna Oschatz, Marcus Maurer and Jörg Haßler}

\begin{abstract}
In this study, we suggest to amending the cognitive mediation model of learning from the news to explain the impact of news coverage on climate change on the recipients' acquisition of knowledge about the consequences of climate change. To test our theoretical assumptions, we combine a content analysis of 29 news media channels with a two-wave panel survey before and after the release of the $5^{\text {th }}$ IPCC report. Results show that the amount of information on the consequences of climate change used in print media and prior knowledge are the strongest predictors of the knowledge in the second panel wave. ${ }^{1}$
\end{abstract}

Keywords

DOI

Environmental communication; Informal learning; Public understanding of science and technology

https://doi.org/10.22323/2.18020207

Submitted: 27th September 2018

Accepted: 29th March 2019

Published: 15th April 2019

Communication about climate change has become an increasingly investigated subject in contemporary communication science [Post, Kleinen-von Königslöw and Schäfer, 2018; Schmid-Petri et al., 2017; Yang and Ho, 2017; Ziegler, 2017]. On the one hand, empirical studies analyze news coverage on climate change. These studies are interested in how causes and consequences of climate change and/or responsibilities and actions to tackle climate change are presented in the news [Hart and Feldman, 2014; Post, Kleinen-von Königslöw and Schäfer, 2018; Schmid-Petri et al., 2017]. On the other hand, studies examine the impact of the exposure to this news coverage on the recipients' knowledge and attitudes about climate change [Kahlor and Rosenthal, 2009; Nisbet, Cooper and Ellithorpe, 2015; Sohlberg, 2017; Yang and Ho, 2017; Ziegler, 2017]. Compared to research on climate change news coverage and its impact on climate change related attitudes, the news media's impact on the acquisition of climate change knowledge received little attention. Examining this impact is important for at least two reasons. First, news media are the most important information sources about climate change as it

\footnotetext{
${ }^{1}$ This publication was created in the context of the research group "Political Communication in the Online World" (1381), subproject 04, which is funded by the Deutsche Forschungsgemeinschaft (DFG, German Research Foundation).
} 
passes the human perception almost unnoticed due to its enormous complexity, huge time spans, and global dimension [Ryghaug, Sørensen and Næss, 2011; Schmidt, Ivanova and Schäfer, 2013]. Second, knowledge on climate change is regarded as a crucial premise for the development of pro-environmental attitudes, behaviors and the publics' support of political decisions related to climate change [Brossard and Lewenstein, 2007; Shi, Visschers and Siegrist, 2015]. However, previous studies on the impact of the news media on the acquisition of knowledge on climate change show rather mixed results. This study aims to clarify some of the heterogeneity and aims to contribute to our understanding of the news media's impact on recipients' climate change knowledge.

We use the cognitive mediation model (CMM) of learning from the news as theoretical framework to explain the impact of climate change news coverage on the recipients' knowledge about climate change. The CMM claims that surveillance gratification seeking positively predicts knowledge gain via two mediators: 1) news attention and 2) elaborative news processing. However, news attention has not been confirmed as relevant mediator of knowledge gain in several empirical studies. Therefore, we suggest to amending the CMM to strengthen its explanatory power by replacing news attention with the amount of individually used news media information on climate change. The degree of self-imposed learning motivation will presumably not only affect how intensively information will be processed but also how many information will be selected from the news. This converges with empirical findings from political communication showing that recipients learn political information the better, the more often they receive this information in the news [Jerit, Barabas and Bolsen, 2006; Shehata and Strömbäck, 2018; Shi, Visschers and Siegrist, 2015; Van Aelst et al., 2017].

We developed a multi-method research design combining a content analysis with a two-wave panel survey before and after the release of the $5^{\text {th }}$ IPCC report published in September 2013 to test our theoretical assumptions. Linking both data sets allows us to calculate the amount of specific climate change information each respondent used between the two panel waves and to analyze the impact of this information on his/her individual knowledge gain. In our study, we focus on the acquisition of knowledge about the consequences of climate change, because this aspect is most frequently discussed in climate change news coverage [Arlt, Hoppe and Wolling, 2011; Dirikx and Gelders, 2008; Hart and Feldman, 2014; Hulme, 2009].

The impact of news media use on the acquisition of climate change knowledge
Since the issue of climate change gained public attention during the 1990s, empirical studies dealt with the question whether media coverage influences public knowledge about climate change. However, previous studies show rather mixed results - especially when the effects of different news media are examined. Early studies examined simple correlations between media use and factual knowledge about scientific and political aspects of climate change. In these studies, newspaper use was positively associated with climate change knowledge. In contrast, heavy television news use was associated with lower levels of knowledge [Stamm, Clark and Eblacas, 2000; Wilson, 1995]. More recent studies also consider online media and apply more conclusive multivariate analysis. Zhao [2009] found that newspaper and internet use positively influenced knowledge, while exposure to television news did not show any effect. In contrast, Kahlor and Rosenthal [2009] found no effects of the use of television and web news. Newspaper use was even 
negatively associated with knowledge about global warming. The authors interpret this finding with presumably inaccurate newspaper reporting but presented no content analysis data to support this assumption. Their results also show that recipients know the more about climate change, the more media channels they use [Kahlor and Rosenthal, 2009]. In an online survey, Taddicken [2013] compared the effects of regular news media use and the use of climate change news coverage, in particular. She found that the use of climate change news coverage on television positively affected knowledge on the causes and consequences of climate change. There was no effect of the use of climate change news coverage in newspapers, radio news, and online news. Moreover, regular news coverage did not influence climate change knowledge at all. Using an online sample from the U.S., Nisbet, Cooper and Ellithorpe [2015] discovered a slightly positive effect of exposure to newspapers but no effect of exposure to television news on climate change knowledge. Finally, comparing the effects of news media use on individuals with high and low socioeconomic status, Yang and Ho [2017] found that especially newspaper reading and watching television news positively affect the acquisition of knowledge about climate change.

These conflicting findings may have several reasons. The studies are conducted in different countries and at different times. They use different measures of media use and different measures of perceived and actual climate change knowledge. Most importantly, we argue that these studies do not consider actual news media content or the individual processing of this content.

Generally, two different theoretical perspectives need to be considered when identifying relevant factors that influence the acquisition of knowledge. Maurer and Oschatz [2015] differentiate an objective perspective and a subjective perspective on the conceptualization of knowledge. The objective perspective is based on learning theories and includes, for example, the knowledge gap hypothesis [Tichenor, Donohue and Olien, 1970]. Empirical studies following this perspective usually analyze direct effects of observable variables (e.g., media use and sociodemographic variables) and focus on information used in different information channels as the most important variable predicting the acquisition of knowledge. The subjective perspective is based on theories from cognitive psychology and includes, for example, the limited capacity model [Lang, 2000]. Empirical studies following this perspective focus on individual information processing as the most important mechanism predicting the acquisition of knowledge and, hence, also consider indirect effects of non-observable variables (e.g., motivational factors and prior attitudes) on the individual knowledge gain. In a nutshell, based on both theoretical perspectives, there are two principle mechanisms underlying the acquisition of knowledge through mass media: the amount of information used in mass media and recipients' individual information processing. This means that the more information recipients receive and the more intensively they process this information, the more knowledge they acquire. A theoretical approach linking both perspectives to some extent is the cognitive mediation model [CMM, Eveland, 2001]. Therefore, we propose the CMM of learning from the news as the theoretical framework for our study. 
The cognitive mediation model of learning from the news
The CMM is an integrated model synthesizing literature from cognitive and educational psychology, the uses and gratifications approach as well as research of learning from the news [Eveland, 2001; Eveland, 2002; Eveland, Shah and Kwak, 2003]. The model highlights the importance of learning motivations for the acquisition of knowledge and uses surveillance gratifications seeking, "the desire to learn from the news" [Eveland, Shah and Kwak, 2003, p. 363], as initial starting point of the learning process. The CMM suggests an indirect impact of the motivation to learn on the acquisition of knowledge through information processing variables. The surveillance motive activates attention to news (the amount of mental focus on news) as well as elaborative processing (integration of new information into existing knowledge). Moreover, the CMM considers news attention as antecedent to elaborative processing as it brings the content to the recipients' consciousness. Following the CMM, greater attention to news and greater elaboration of the news should lead to higher levels of learning. These theoretical assumptions have been confirmed in various fields of communication research such as political communication [Eveland, 2001], health communication [Ho, Peh and Soh, 2013; Lee et al., 2016], and science communication [Ho, Yang et al., 2017; Yang, Chuah et al., 2017]. However, the model received various amendments of the initial learning motivation, the mediating processes as well as the considered outcomes [Ho, Yang et al., 2017; Lee et al., 2016; Wei and Lo, 2008; Yang and Ho, 2017; Yang, Chuah et al., 2017; Zhao et al., 2011]. The most profound suggestions for modifications address the mediating processes. While elaborative processing is broadly confirmed as relevant mediator of the acquisition of knowledge [Eveland, 2001; Fleming and Thorson, 2008; Lee et al., 2016; Yang and Ho, 2017], news attention is discussed critically, because it is not consistently confirmed as a mediator [Jensen, 2011; Wei and Lo, 2008; Yang, Chuah et al., 2017; Zhao et al., 2011]. For example, Zhao and co-authors [2011] argue that news attention has to be measured more precisely, as attention to political news causes different effects than attention to environmental news. More specifically, Wei and Lo [2008] point out that the CMM considers news media use as a precondition but fails to include this variable in the model. Thus, they expand the CMM including media exposure to print, television, and online news in addition to news attention. The results confirm that exposure to print and television news is a mediator of knowledge gain. No such finding occurred for news attention to either media channel.

Acknowledging these prior amendments, we suggest that there is an implicit assumption in the CMM that has not been addressed so far. Gaining knowledge from the news on a specific topic requires the occurrence of specific information on that topic in the news. This is a necessary precondition for knowledge gain. Attention to a 'sparse' news environment on the topic being addressed will not mediate the acquisition of knowledge, which can explain the heterogeneous empirical findings on attention to news as mediator of knowledge gain. We argue that individuals strongly engaging in seeking surveillance gratifications - "those pertaining to gaining information about one's environment" [Eveland, 2001, p. 575] will engage in collecting more information than recipients with a low surveillance gratification seeking motivation. Hence, the amount of individually used news information on a specific topic will mediate the acquisition of knowledge on this topic. This assumption converges with theoretical approaches and empirical findings like the knowledge gap hypothesis [Tichenor, Donohue and Olien, 1970] that aim to explain the acquisition of long-term political knowledge. From various 
studies in this line of research it is known that individuals learn (political) information the better, the more often they receive this information in the news [e.g., Jerit, Barabas and Bolsen, 2006; Shehata and Strömbäck, 2018; Van Aelst et al., 2017]. Therefore, we suggest to replacing news attention with the amount of individually used news media information.

Research model and hypotheses
According to the CMM, individual learning motivation is crucial for the acquisition of knowledge. Studies using the CMM as a theoretical basis show that surveillance gratification seeking is associated with knowledge gain by positively predicting elaborative news processing [Eveland, 2001; Eveland, Shah and Kwak, 2003]. In addition, as has been proposed above, surveillance gratification seeking should as well predict the amount of individually used news media information.
H1: Surveillance gratification seeking positively predicts elaborative information processing.
$H 2$ : Surveillance gratification seeking positively predicts the amount of individually used news media information on the consequences of climate change in print, television, and online media.

The CMM considers news attention as antecedent to elaborative processing as content cannot be processed without being received in the first place [Eveland, 2001; Jensen, 2011; Yang, Chuah et al., 2017]. This argument also applies to our amended model as we replace the attention to news with the amount of individually used news media content.

H3: The amount of individually used news media information on the consequences of climate change positively predicts elaborative information processing.

Research on the CMM consistently found that elaborative information processing mediates the acquisition of knowledge [Eveland, 2001; Ho, Yang et al., 2017; Yang, Chuah et al., 2017]. As well, previous studies in political communication confirm the amount of individually used news media information as an important variable that determines the acquisition of knowledge [Kahlor and Rosenthal, 2009; Shehata and Strömbäck, 2018; Taddicken, 2013; Van Aelst et al., 2017].

H4: Elaborative information processing positively predicts the acquisition of knowledge on the consequences of climate change.

H5: The amount of individually used news media information on the consequences of climate change in print, television, and online media positively predicts the acquisition of knowledge on the consequences of climate change.

Finally, we add two hypotheses on the role of previous knowledge for learning from the news. In the only panel study testing the CMM, Eveland, Shah and Kwak [2003] confirm previous knowledge at time 1 as the strongest predictor of knowledge at time 2. Moreover, it can be assumed that prior knowledge also affects 
the intensity of elaborative processing. Elaboration is the "process of connecting new information to other information stored in memory" [Eveland, 2001, p. 573]. Psychological models like the limited capacity model [Lang, 2000] postulate that the intensity of the elaboration increases, the more an individual already knows as less cognitive resources are required to elaborate new information.

H6: Previous knowledge on the consequences of climate change positively predicts the intensity of elaborative processing of new information on the consequences of climate change.

H7: The level of previous knowledge on the consequences of climate change at time 1 positively predicts the level of knowledge at time 2 .

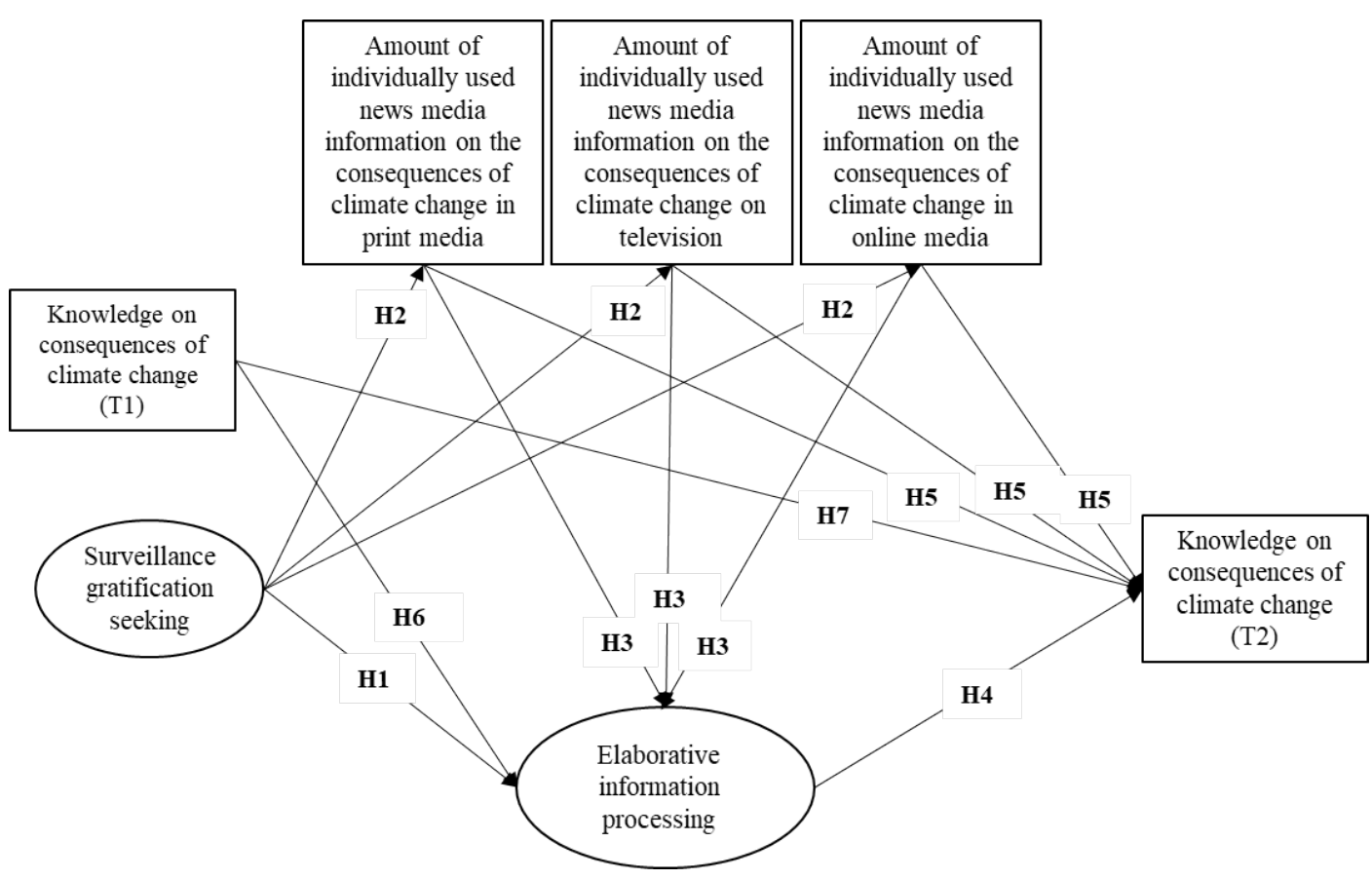

Figure 1. Research model.

To test our hypotheses, we developed a multi-method research design combining a content analysis on news media coverage on the consequences of climate change from the first part of the $5^{\text {th }}$ IPCC report with a two-wave panel survey interviewing 529 respondents before and after the release of the report.

\section{Panel survey}

The first panel wave (T1) was conducted directly prior the release of the IPCC report on September 27, 2013 (16 to 23 September), the second panel wave (T2) directly after the release ( 30 September to 8 October). The interviews were conducted by telephone, using the random-last-digit method to create a random sample. Previous findings show that regional daily newspapers are an important information source for many German citizens [Hasebrink and Schmidt, 2013]. As it is not possible to consider all German regional newspapers in our content analysis, 
we draw a regional sample from the inhabitants of a German university town of legal age.

The questionnaire consisted of five elements: (1) A knowledge question on the consequences of climate change, (2) questions on individual media use, (3) a scale to assess surveillance gratification seeking, (4) a scale to measure elaborative information processing, and (5) items to record sociodemographic variables and party identification.

Knowledge on the consequences of climate change was measured with an open-ended question in both panel waves. The respondents were asked to list as many consequences of climate change as they could think of ("What are the consequences of climate change? What will change on earth? Please list as many consequences as you can think of $\left.{ }^{\prime \prime}\right)$. We evaluated all consequences that were mentioned in the IPCC report as correct answers and calculated the sum of these correct answers for each respondent in each of the two panel waves. Correct answers given in $\mathrm{T} 1(M=3.1, S D=1.82)$ were used in the analyses as independent variable reflecting previous knowledge; correct answers given in T2 $(M=3.3, S D=1.91)$ were used as dependent variable.

To be able to explain differences in knowledge about the consequences of climate change between T1 and T2 with the individually used amount of information about the consequences of climate change, we need to carefully match the panel data and content analysis. Therefore, we included a set of detailed questions on the exposure to climate change information to determine the most important information sources and the frequency of their use in the $2^{\text {nd }}$ panel wave. We determined for 41 news outlets how often they were used by each respondent to inform themselves about climate change ( $1=$ "daily/every issue", 2 = "almost daily/in almost every issue", 3 = "on occasion", $4=$ "never"). These 41 outlets are composed of 32 news media outlets that are most commonly used by German citizens (including the regional daily newspapers) and complemented with nine information sources by political parties and scientific organizations one is likely to use when searching for information about climate change. In addition, we asked an open-ended question to measure whether our respondents used any additional information sources. Only 29 media outlets were used by a considerable number of participants and were therefore included in the content analysis.

Surveillance gratification seeking was measured with four items on a four point Likert scale ( 1 = "does not apply", 4 = "applies completely") in the first panel wave. Items were taken from Eveland [2001]: I use mass media to (1) stay in touch with the world, (2) form an opinion on politics, (3) find out about the main events of the day, (4) make up my mind about current events. Item 1 was dropped to improve internal consistency (Cronbachs $\alpha=.70, M=2.87, S D=.56$ ).

The measure for elaborative information processing consists of three items and was based on Schemer, Matthes and Wirth [2008]. Items were measured on a 4-point Likert scale and determined how closely our respondents follow the information on climate change $(1=$ "does not apply", $4=$ "applies completely"): (1) It is important to me to inform myself about climate change, (2) I closely follow news reports on climate change, (3) If I come across news reports on climate change I usually read them very carefully (Cronbach's $\alpha=.76, M=3.02, S D=.69$ ). 
Finally, we recorded the respondents' educational level, age, gender, and party identification. 864 interviews were completed in the first panel wave (response rate: $28 \%$ ), 554 interviews in the second wave (response rate: $64 \%$ ). After excluding 25 respondents due to missing data, 529 remained in the final sample. Males (46\%) and females (54\%) are about equally presented. With an average age of 57 , the sample is slightly older than the average population in the town of data collection. Furthermore, typical for a small town with a large university, the sample is rather highly educated: two-thirds obtained a higher-level education (at least A-levels).

\section{Content analysis}

Media coverage on climate change was analyzed between September 20 (one week prior the release of the IPCC report) and the October 8, 2013 (ten days after the release of the report). Based on the results of the media exposure questions in our survey, we conducted a content analysis of the 29 most frequently used media outlets. We did not include information distributed by political parties and scientific organizations, as only a few respondents reported using these sources. The print media sample consisted of four national broadsheet newspapers (Frankfurter Allgemeine Zeitung, Süddeutsche Zeitung, Die Welt, Frankfurter Rundschau), one tabloid newspaper (Bild-Zeitung), the three regional newspapers published at the location of examination (Ostthüringer Zeitung, Thüringer Allgemeine, Thüringer Landeszeitung), and two weekly news magazines (Der Spiegel, Focus). The television sample consisted of the daily evening news of the two widest-reaching public and private TV stations (ARD Tagesschau, ZDF heute, RTL aktuell, Sat1 Nachrichten). The online news media sample consisted of these offline media's websites, complemented by the most frequently used online news portal web.de.

Newspapers were obtained from the university library archive. Television news were recorded by the university's multimedia center. We developed the database ARTICLe (ㅅutomatic RSS-crawling Tool for Internet-based Content anaLysis) to collect online articles despite the volatility of online media. Every two hours, starting from the websites' RSS-feeds, newly published online articles were automatically stored [Haßler, Maurer and Holbach, 2014].

The codebook was developed in a broader research project that examined how the media and political information sources represent new information about climate change during major climate events like the UN climate summits or the publication of the IPCC report. Overall, the codebook consisted of 64 categories analyzing how scientific aspects of climate change like the causes and consequences of climate change as well as political aspects like responsibilities and actions to tackle climate change are represented in the news. For the current study, only the consequences of climate change are relevant, as this was matched with the knowledge question in our panel survey. The coding was conducted manually by five well-trained student coders. They coded up to five different consequences of climate change for each news report. In case more than five consequences were mentioned in one report, the five consequences presented most prominently (e.g., in more details) and most frequently were coded. The test of the intercoder reliability of the coding of consequences revealed a Krippendorff's alpha of .84 . 


\section{Linking content analysis and panel data}

We linked the data of the content analysis (amount of consequences mentioned in each of the 29 news media) and the panel survey (each respondent's exposure to the 29 news media) using a technique that was developed in the context of studies on media effects on voting intentions [e.g., Kleinnijenhuis et al., 2001]. For this purpose, we assigned the amount of consequences of climate change mentioned in each news media outlet between the first and the second panel wave to each respondent who used that outlet. The full amount of consequences mentioned was assigned to respondents stating that they used an outlet "daily/every issue". For respondents using the news outlet "almost daily/almost every issue" the data was weighted with the factor 0.75 and respectively with the factor 0.25 if they used the outlet "on occasion". Afterwards, we calculated the total sum of all the information on the consequences of climate change each respondent used in print $(M=3.49$, $S D=4.15)$, television $(M=1.98, S D=2.90)$, and online news media $(M=4.53$, $S D=10.40)$. The grouping is conducted to contribute to understanding the heterogeneous findings of previous studies showing that the impact of climate change news coverage on the acquisition of knowledge depends to a large extent on the media channel used. The result of this grouping is an index that approximately expresses how often each individual respondent used information on the consequences of climate change in each of the three media channels between the two panel waves. For example, imagine that one of the panel respondents reads two newspapers every day. The content analysis shows that one newspaper mentioned 20 consequences of climate change and the other one mentioned 10. This respondent's index value is $30(20 \times 1+10 \times 1)$, which means that 30 consequences presumably consumed between the two panel waves were assigned to this respondent. Consequently, he/she is assumed to learn more about the consequences of climate change compared to another respondent reading only the first newspaper on occasion (index value: $20 \times 0.25=5$ ).

\section{Results}

\section{News coverage on the consequences of climate change}

The 29 news outlets published 186 reports on climate change in the investigation period. Online news media released 115 articles, print news published 63 news stories, and television news broadcasted eight reports. Overall, 101 reports mentioned consequences of climate change. In total, the news reports mentioned 316 consequences of climate change as up to five different consequences could have been coded for each news report (Figure 2). Most of them were mentioned in online news media $(n=202)$, followed by print media $(n=93)$, and television news $(n=21)$. Across all media channels, the three most frequently mentioned consequences were the rising sea levels $(n=56)$, the long-term temperature rise $(n=51)$, and the melting of polar caps and ice shields $(n=32)$.

Compared to the news attention to the previous IPCC report published in March 2007, the news coverage is extremely low: the International Collective on Environment, Culture \& Politics (ICE CaPs) continuously tracks the global news media coverage on climate change and reports considerably more news coverage for the previous report [Boykoff et al., 2019]. We see two major reasons for the decline of news attention to the issue of climate change. First, this finding confirms a global trend of a general decrease in news media coverage on climate change 


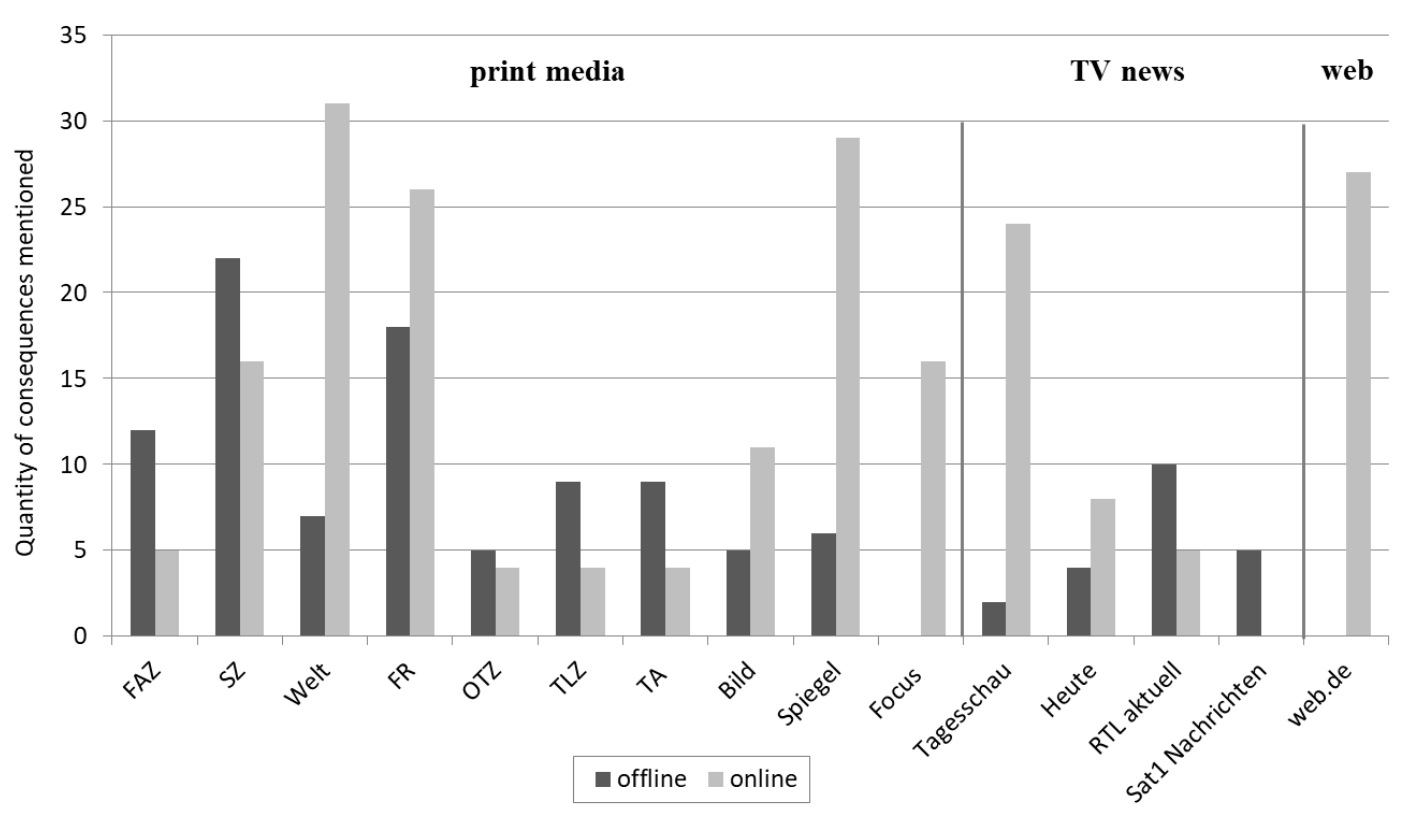

Note: content analysis of the news coverage online and offline on the first part of the $5^{\text {th }}$ IPCC report from $09 / 20 / 2013$ until 10/08/2013 $(N=316)$.

Figure 2. Media coverage on the consequences of climate change.

[Boykoff et al., 2019]. Moreover, the German National Election took place about one week prior the release. Due to its unexpected results, the election was still the most important media issue in Germany one week after.

Nerws media use on the consequences of climate change

On average, our respondents were exposed to four of the 29 information sources at least occasionally. Figure 3 shows that the vast majority was exposed to television news, especially the two public broadcasting channels. About 40 percent read articles on climate change in regional newspapers. Online information sources were used considerably less often. Therefore, the fact that online news media report on climate change most frequently is counteracted by the fact that most people do not receive information on climate change from online news media.

\section{The acquisition of knowledge about the consequences of climate change}

Results show that our respondents acquired knowledge on the consequences of climate change between the two panel waves. On an aggregate level, the respondents were able to list on average 3.1 consequences of climate change in the first and 3.3 consequences in the second wave $(t(529)=1,991, p=.047)$. On the individual level, 41 percent of the respondents were able to list more consequences of climate change in the second compared to the first panel wave.

We tested the causal claims of our predictive research model with structural equation modeling (Amos 24.0) using maximum likelihood estimation. Surveillance gratification seeking and elaborative information processing were introduced as latent constructs. As well, we controlled for the effects of gender, age, 


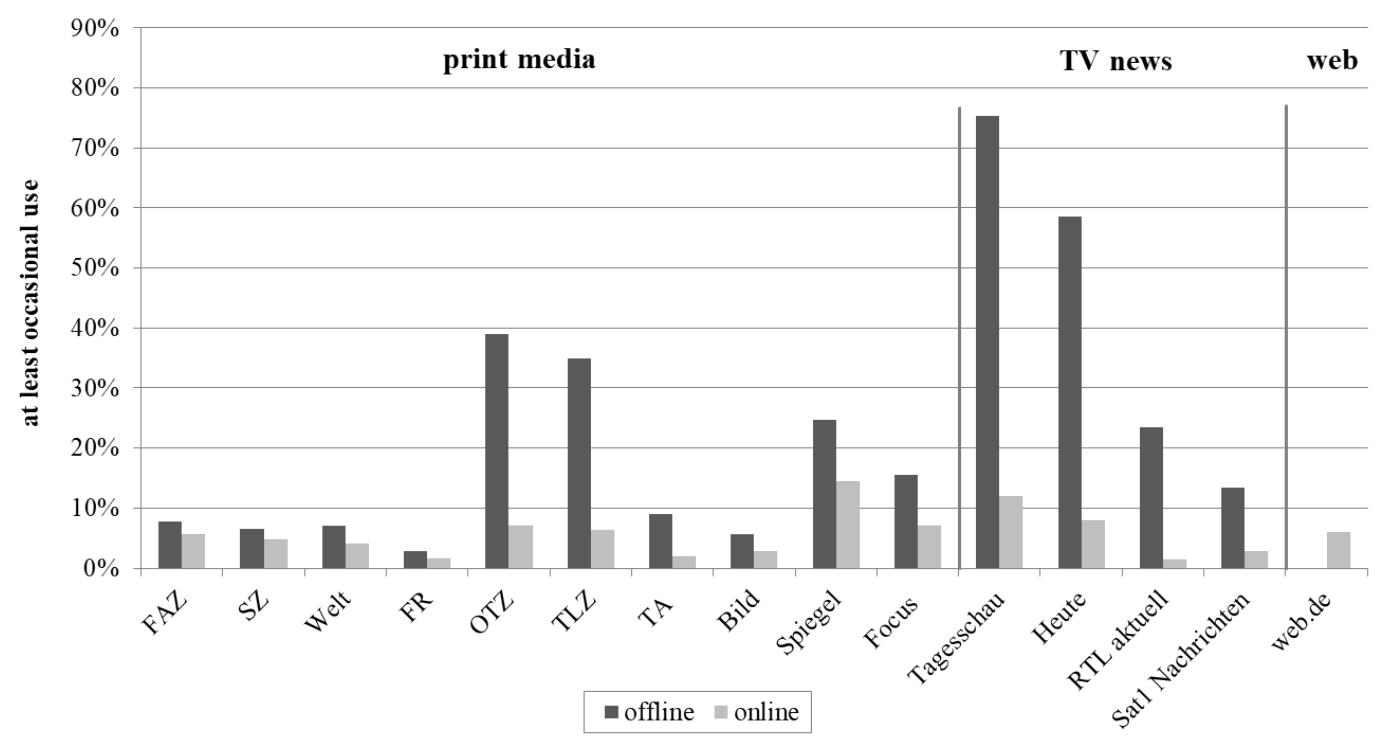

Note: panel survey from 09/16/2013 until 09/23/2013 (T1) and from 09/30/2013 until 10/08/2013 (T2).

Figure 3. News media use on climate change.

education, and party identification. Model estimates are presented in Figure 4. For clarity of presentation, non-significant paths are not included (RMSEA $=.031,90 \%$ $\mathrm{CI}$ of RMSEA $=.018-.044, \mathrm{SRMR}=.0386, \mathrm{CFI}=.973)$.

$H 1$ and $H 2$ address the impact of surveillance gratification seeking as learning motivation on the mediating processes. $H 1$ is supported by the data as surveillance gratification seeking positively predicts elaborative information processing $(\beta=.19, p=.001)$. This result is in line with the predictions of the CMM. As well, $\mathrm{H} 2$ is confirmed as surveillance gratification seeking positively predicts the amount of individually used news media information on the consequences of climate change in print $(\beta=.20, p<.001)$ and television news $(\beta=.16, p=.001)$. Contrary to our hypothesis, surveillance gratification seeking did not predict the amount of information used in online media $(\beta=.07, p=.122)$. $\mathrm{H3}$ assumes that the amount of individually used news media information on the consequences of climate change positively predicts elaborative information processing. The data confirm our hypotheses for print $(\beta=.14, p=.004)$ and online media $(\beta=.13$, $p=.010)$, but not for television news $(\beta=.07, p=.148)$. This finding is line with research on the knowledge gap hypothesis suggesting that television news require less intensive elaboration than print and online news media [Grabe, Kamhawi and Yegiyan, 2009]. $H 4$ and $H 5$ postulate that elaborative information processing as well as the amount of individually used news media information on the consequences of climate change positively predict the acquisition of knowledge. Hypothesis $\mathrm{H} 4$ is not supported by the data. An increase in the intensity of elaborative information processing did not result in an increase in knowledge about the consequences of climate change $(\beta=.09, p=.072)$. In the CMM, elaboration also serves as a mediator of indirect effects on the acquisition of knowledge. Therefore, we tested whether elaborative processing mediates the indirect effect of (1) surveillance gratification seeking and (2) the amount of individually used information on the acquisition of knowledge. The results confirm 
that elaborative processing remains a key tenet of the amended CMM as an increase in the level of surveillance gratification seeking $\left(a \times b_{\text {standardized }}=.017\right.$, $p=.005)$ as well as the amount of information used in print $\left(a \times b_{\text {standardized }}=.013\right.$, $p=.034)$ and online media $\left(a \times b_{\text {standardized }}=.012, p=.045\right)$ indirectly increased the recipients' knowledge about the consequences of climate change via elaborative processing. Hypothesis $\mathrm{H} 5$ is partly confirmed as amount of individually used news media information on the consequences of climate change in print media positively predicts the acquisition of knowledge on the consequences of climate change $(\beta=.13, p<.001)$. No such finding occurred for the amount of information used on television $(\beta=-.03, p=0.444)$ or in online media $(\beta=-.01$, $p=.747)$. The results can most likely be explained by a combination of findings from our content analyses and panel survey, as television news did not disseminate much information on the consequences of climate change and online media have not frequently been used. Consequently, only print media provided an information environment that promoted the acquisition of knowledge.

Finally, $\mathrm{H6}$ and $\mathrm{H} 7$ address the role of previous knowledge. $\mathrm{H} 6$ is confirmed by the data as previous knowledge on the consequences of climate change (T1) positively predicts the intensity of elaborative processing of new information on the consequences of climate change $(\beta=.31, p<.001)$. Moreover, $H 7$ is confirmed as the level of previous knowledge on the consequences of climate change at time 1 positively predicts the level of knowledge at time $2(\beta=.43, p<.001)$. Previous knowledge at T1 even emerged as the strongest predictor of the knowledge at T2.

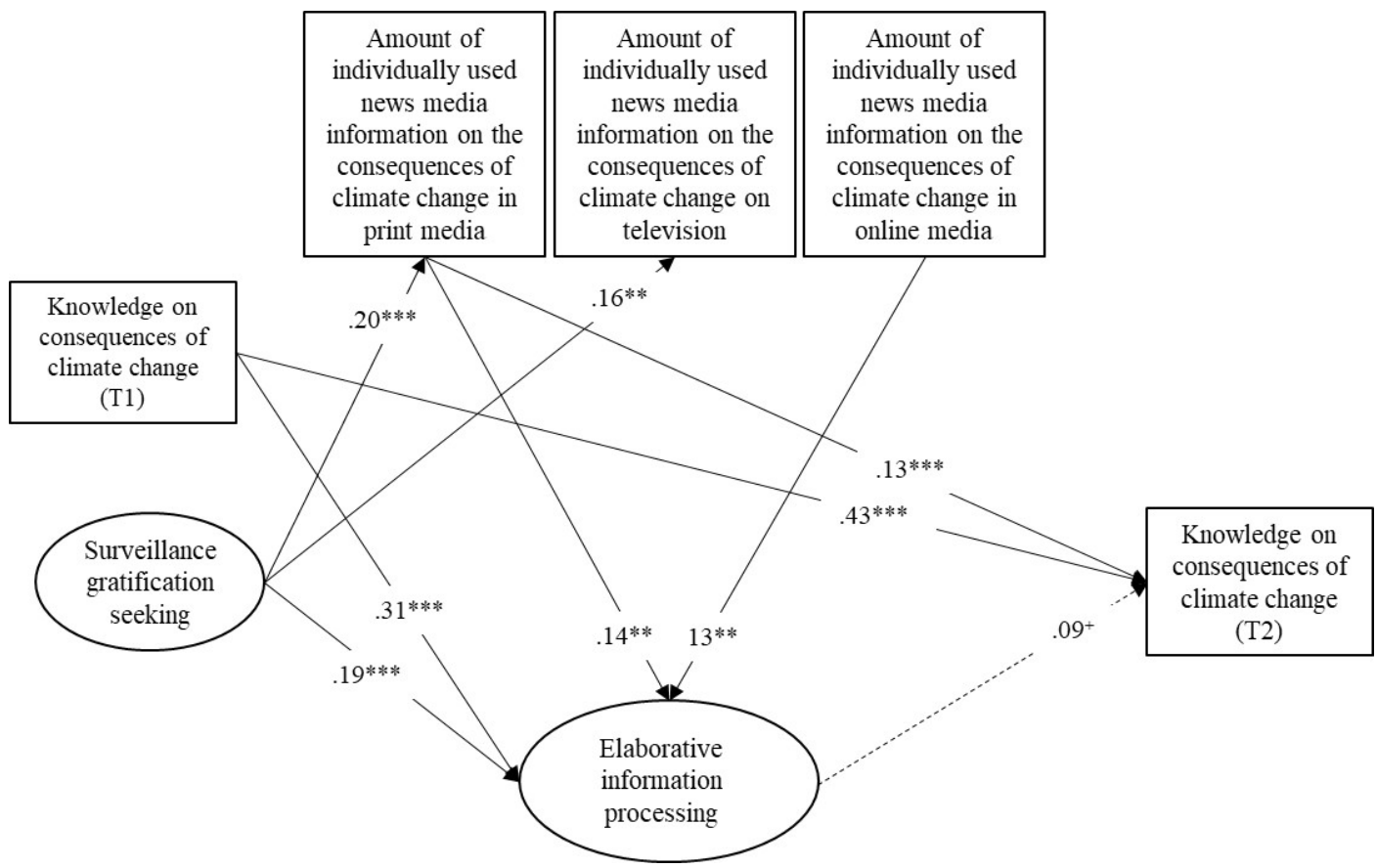

Notes: displayed are standardized estimates controlling for age, gender, education, and party identification. Ovals represent latent variables. Rectangles represent observed variables. Non-significant path are excluded. $(N=529),{ }^{+} \mathrm{p}<.10,{ }^{*} p<.05,{ }^{* *} p<.01,{ }^{* * *} p<.001$, Model fit: RMSEA $=.031,90 \%$ CI of RMSEA $=.018-.044, \mathrm{SRMR}=.0386, \mathrm{CFI}=.973$.

Figure 4. Factors influencing knowledge acquisition on the consequences of climate change. 
In this study, we amended the cognitive mediation model of learning from the news to explain the acquisition of knowledge on the consequences of climate change. Specifically, we replaced news attention with the amount of individually used information on the consequences of climate change. To test our theoretical assumptions, we combined a content analysis of the media coverage on the release of the $5^{\text {th }}$ IPCC report in 29 print, television and online news media outlets with a two-wave panel survey of 529 adult respondents that were interviewed shortly before and after the news addressed the report. To measure the impact of the individually used news media content on knowledge gain, we linked content analysis and survey data on the individual level.

The analyses show that print media, television news, and online news media did not extensively report on the consequences of climate change. Nevertheless, in the second panel wave, 41 percent of the respondents were able to list more consequences of climate change than in the first panel wave. In line with the assumption of the amended cognitive mediation model, surveillance gratification seeking predicted the amount of information on the consequences of climate change used as well as elaborative processing. Moreover, we found an effect of the amount of information about the consequences of climate change used in print media on the acquisition of knowledge on the consequences of climate change. No such effect occurred for television news and online news media. Elaborative processing did not directly predict the acquisition of knowledge, but was confirmed as relevant mediator as indirect effects occurred from surveillance gratification seeking and the amount of information used in print and online media.

The study contributes to our theoretical understanding of learning from the news. Based on the objective and subjective perspective of the conceptualization of knowledge, we suggest that there are two essential mechanisms that foster the acquisition of knowledge. The more information an individual receives (amount of information) and the more intense this information is processed with (elaboration), the greater is the acquisition of knowledge. We integrate both lines of research in the cognitive mediation model by replacing news attention with the actual amount of news media information. Thereby, we shed light on an implicit assumption of the cognitive mediation model that accepts the occurrence of specific information in the news as a premise. Attention to a 'sparse' news environment on the topic being addressed will not mediate the acquisition of knowledge, which can explain the heterogeneous empirical findings on attention to news as mediator of knowledge gain. Associated therewith, the amendment of the CMM allows examining the differential effects of different news media channels on the acquisition of knowledge.

This paper also makes a valuable contribution to the field of science communication. It adds to our understanding of how and how much lay people learn from the mass media about environmental issues like climate change. This is achieved by applying the fruitful combination of content analysis and panel survey that allows for a better understanding of small effects of news media use on knowledge gain. The overall small effects can be attributed to the finding that television news did not disseminate much information on the consequences of climate change and online media have not frequently been used. Consequently, only print media caused a considerable increase in knowledge. Future studies should continue to consider actual news media content to further clarify the heterogeneous findings in this field of research. 
The design of the study also involves some limitations. As mentioned above, we can only approximate the amount of individually used information. Although we measured news media use very detailed, we only included the most frequently used news media in the content analysis. Moreover, using a study design such as ours is afflicted with many risks. The first panel wave had to be conducted before we knew whether and how the different news media would report on the consequences of climate change. In our case, news media did not report a lot on climate change as the release of the report was repeatedly postponed, and, finally, arrived on the Friday after the German national election.

\section{Conclusion}

In summary, even though the effects of the used mass media content on the acquisition of knowledge are small, the results are not discouraging. Many respondents already showed profound previous knowledge on the consequences of climate change in the first panel wave. It is more than likely that this previous knowledge originates in a large part from mass media use as there are almost no other sources of climate change information.

\section{References}

Arlt, D., Hoppe, I. and Wolling, J. (2011). ‘Climate change and media usage: effects on problem awareness and behavioural intentions'. International Communication Gazette 73 (1-2), pp. 45-63. https: //doi.org/10.1177/1748048510386741.

Boykoff, M., Daly, M., McAllister, L., McNatt, M., Nacu-Schmidt, A., Oonk, D. and Pearman, O. (2019). German newspaper coverage of climate change or global warming, 2004-2018. URL: http://sciencepolicy.colorado.edu/media_coverage.

Brossard, D. and Lewenstein, B. (2007). 'A critical approach of models of public understanding of science: using practice to inform theory'. In: The media, the public and agricultural biotechnology. Ed. by D. Brossard, J. Shanahan and T. C. Nesbitt. Wallingford, U.K.: CABI.

Dirikx, A. and Gelders, D. (2008). 'Newspaper communication on global warming: different approaches in the U.S. and the E.U.?' In: Communicating climate change: discourses, mediations and perceptions. Ed. by A. Carvalho. Braga, Portugal: Centro de Estudos de Comunicação e Sociedade (CECS), Universidade do Minho, pp. 98-109.

Eveland, W. P. (2001). 'The cognitive mediation model of learning from the news: evidence from nonelection, off-year election and presidential election contexts'. Communication Research 28 (5), pp. 571-601. https://doi.org/10.1177/009365001028005001.

- (2002). 'News information processing as mediator of the relationship between motivations and political knowledge'. Journalism $\mathcal{E}$ Mass Communication Quarterly 79 (1), pp. 26-40. https://doi.org/10.1177/107769900207900103.

Eveland, W. P., Shah, D. V. and Kwak, N. (2003). 'Assessing causality in the cognitive mediation model: a panel study of motivations, information processing and learning during campaign 2000'. Communication Research 30 (4), pp. 359-386. https://doi.org/10.1177/0093650203253369.

Fleming, K. and Thorson, E. (2008). 'Assessing the role of information-processing strategies in learning from local news media about sources of social capital'. Mass Communication and Society 11 (4), pp. 398-419. https://doi.org/10.1080/15205430801950643.

Grabe, M. E., Kamhawi, R. and Yegiyan, N. (2009). 'Informing citizens: how people with different levels of education process television, newspaper and web news'. Journal of Broadcasting $\mathcal{E}$ Electronic Media 53 (1), pp. 90-111. https://doi.org/10.1080/08838150802643860. 
Hart, P. S. and Feldman, L. (2014). 'Threat without efficacy? Climate change on U.S. network news'. Science Communication 36 (3), pp. 325-351.

https://doi.org/10.1177/1075547013520239.

Hasebrink, U. and Schmidt, J.-H. (2013). 'Medienübergreifende

Informationsrepertoires. Zur Rolle der Mediengattungen und einzelner Angebote für Information und Meinungsbildung'. [Overarching media repertoires. On the role of media genre and specific columns and broadcastings for information and opinion formation]. Media Perspektiven, pp. 2-12.

Haßler, J., Maurer, M. and Holbach, T. (2014). 'Vorsprung durch Technik? Die Analyse journalistischer Online-Angebote mit Hilfe automatisierter Verfahren'. [The technical edge? The analysis of journalistic online offers with the help of automated procedures]. Studies in Communication | Media 3 (2), pp. 180-204. https://doi.org/10.5771/2192-4007-2014-2-180.

Ho, S. S., Peh, X. and Soh, V. W. L. (2013). 'The cognitive mediation model: factors influencing public knowledge of the H1N1 pandemic and intention to take precautionary behaviors'. Journal of Health Communication 18 (7), pp. 773-794. https://doi.org/10.1080/10810730.2012.743624.

Ho, S. S., Yang, X., Thanwarani, A. and Chan, J. M. (2017). 'Examining public acquisition of science knowledge from social media in Singapore: an extension of the cognitive mediation model'. Asian Journal of Communication 27 (2), pp. 193-212. https://doi.org/10.1080/01292986.2016.1240819.

Hulme, M. (2009). 'Mediating the messages about climate change'. In: Climate change and the media. Ed. by T. Boyce and J. Lewis. New York, U.S.A.: Peter Lang, pp. 117-128.

Jensen, J. D. (2011). 'Knowledge acquisition following exposure to cancer news articles: a test of the cognitive mediation model'. Journal of Communication 61 (3), pp. 514-534. https://doi.org/10.1111/j.1460-2466.2011.01549.x.

Jerit, J., Barabas, J. and Bolsen, T. (2006). 'Citizens, knowledge and the information environment'. American Journal of Political Science 50 (2), pp. 266-282. https://doi.org/10.1111/j.1540-5907.2006.00183.x.

Kahlor, L. and Rosenthal, S. (2009). 'If we seek, do we learn?' Science Communication 30 (3), pp. 380-414. https://doi.org/10.1177/1075547008328798.

Kleinnijenhuis, J., Maurer, M., Kepplinger, H. M. and Oegema, D. (2001). 'Issues and personalities in German and Dutch television news'. European Journal of Communication 16 (3), pp. 337-359. https://doi.org/10.1177/0267323101016003003.

Lang, A. (2000). 'The limited capacity model of mediated message processing'. Journal of Communication 50 (1), pp. 46-70. https://doi.org/10.1111/j.1460-2466.2000.tb02833.x.

Lee, E. W. J., Shin, M., Kawaja, A. and Ho, S. S. (2016). 'The augmented cognitive mediation model: examining antecedents of factual and structural breast cancer knowledge among singaporean women'. Journal of Health Communication 21 (5), pp. 583-592. https://doi.org/10.1080/10810730.2015.1114053.

Maurer, M. and Oschatz, C. (2015). 'The influence of online media on political knowledge'. In: Political communication in the online world. Theoretical approaches and research designs. Ed. by G. Vowe and P. Henn. New York, U.S.A.: Routledge, pp. 73-87. https://doi.org/10.4324/9781315707495-6.

Nisbet, E. C., Cooper, K. E. and Ellithorpe, M. (2015). 'Ignorance or bias? Evaluating the ideological and informational drivers of communication gaps about climate change'. Public Understanding of Science 24 (3), pp. 285-301.

https://doi.org/10.1177/0963662514545909. 
Post, S., Kleinen-von Königslöw, K. and Schäfer, M. S. (2018). 'Between guilt and obligation: debating the responsibility for climate change and climate politics in the media'. Environmental Communication 2, pp. 1-17. https://doi.org/10.1080/17524032.2018.1446037.

Ryghaug, M., Sørensen, K. H. and Næss, R. (2011). 'Making sense of global warming: Norwegians appropriating knowledge of anthropogenic climate change'. Public Understanding of Science 20 (6), pp. 778-795. https://doi.org/10.1177/0963662510362657.

Schemer, C., Matthes, J. and Wirth, W. (2008). 'Toward improving the validity and reliability of media information processing measures in surveys'. Communication Methods and Measures 2 (3), pp. 193-225. https://doi.org/10.1080/19312450802310474.

Schmid-Petri, H., Adam, S., Schmucki, I. and Häussler, T. (2017). 'A changing climate of skepticism: the factors shaping climate change coverage in the U.S. press'. Public Understanding of Science 26 (4), pp. 498-513. https://doi.org/10.1177/0963662515612276.

Schmidt, A., Ivanova, A. and Schäfer, M. S. (2013). 'Media attention for climate change around the world: A comparative analysis of newspaper coverage in 27 countries'. Global Environmental Change 23 (5), pp. 1233-1248. https://doi.org/10.1016/j.gloenvcha.2013.07.020.

Shehata, A. and Strömbäck, J. (2018). ‘Learning political news from social media: network media logic and current affairs news learning in a high-choice media environment'. Communication Research, p. 009365021774935. https://doi.org/10.1177/0093650217749354.

Shi, J., Visschers, V. H. M. and Siegrist, M. (2015). 'Public perception of climate change: the importance of knowledge and cultural worldviews'. Risk Analysis 35 (12), pp. 2183-2201. https://doi.org/10.1111/risa.12406.

Sohlberg, J. (2017). 'The effect of elite polarization: a comparative perspective on how party elites influence attitudes and behavior on climate change in the European Union'. Sustainability 9 (1), p. 39. https://doi.org/10.3390/su9010039.

Stamm, K. R., Clark, F. and Eblacas, P. R. (2000). 'Mass communication and public understanding of environmental problems: the case of global warming'. Public Understanding of Science 9 (3), pp. 219-237. https://doi.org/10.1088/0963-6625/9/3/302.

Taddicken, M. (2013). ‘Climate change from the user's perspective: the impact of mass media and internet use and individual and moderating variables on knowledge and attitudes'. Journal of Media Psychology 25 (1), pp. 39-52. https://doi.org/10.1027/1864-1105/a000080.

Tichenor, P. J., Donohue, G. A. and Olien, C. N. (1970). 'Mass media flow and differential growth in knowledge'. Public Opinion Quarterly 34 (2), p. 159. https://doi.org/10.1086/267786.

Van Aelst, P., Strömbäck, J., Aalberg, T., Esser, F., Vreese, C. de, Matthes, J., Hopmann, D., Salgado, S., Hubé, N., Stępińska, A., Papathanassopoulos, S., Berganza, R., Legnante, G., Reinemann, C., Sheafer, T. and Stanyer, J. (2017). 'Political communication in a high-choice media environment: a challenge for democracy?' Annals of the International Communication Association 41 (1), pp. 3-27. https://doi.org/10.1080/23808985.2017.1288551.

Wei, R. and Lo, V.-H. (2008). 'News media use and knowledge about the 2006 U.S. midterm elections: why exposure matters in voter learning'. International Journal of Public Opinion Research 20 (3), pp. 347-362. https://doi.org/10.1093/ijpor/edn032. 
Wilson, K. M. (1995). 'Mass media as sources of global warming knowledge'. Mass Communication Review 22, pp. 75-89.

Yang, X., Chuah, A. S. F., Lee, E. W. J. and Ho, S. S. (2017). 'Extending the cognitive mediation model: examining factors associated with perceived familiarity and factual knowledge of nanotechnology'. Mass Communication and Society 20 (3), pp. 403-426. https://doi.org/10.1080/15205436.2016.1271436.

Yang, X. and Ho, S. S. (2017). 'Decreasing the knowledge gap among different socioeconomic status groups on the issue of climate change'. Environmental Hazards 16 (3), pp. 276-290. https://doi.org/10.1080/17477891.2017.1279999.

Zhao, X. (2009). 'Media use and global warming perceptions: a snapshot of the reinforcing spirals'. Communication Research 36 (5), pp. 698-723. https://doi.org/10.1177/0093650209338911.

Zhao, X., Leiserowitz, A. A., Maibach, E. W. and Roser-Renouf, C. (2011). 'Attention to science/environment news positively predicts and attention to political news negatively predicts global warming risk perceptions and policy support'. Journal of Communication 61 (4), pp. 713-731. https://doi.org/10.1111/j.1460-2466.2011.01563.x.

Ziegler, A. (2017). 'Political orientation, environmental values and climate change beliefs and attitudes: an empirical cross country analysis'. Energy Economics 63, pp. 144-153. https://doi.org/10.1016/j.eneco.2017.01.022. Department of Psychology / Institute for Communication and Media Psychology at the University of Koblenz-Landau. E-mail: oschatz@uni-landau.de.

Marcus Maurer, Ph.D., is Professor and Chair for Political Communication at the Department of Communication at the Johannes Gutenberg-University of Mainz. E-mail: mmaurer@uni-mainz.de.

Jörg Haßler, Ph.D., is the Leader of the ZD.B-Junior-Research-Group “Digital Democratic Mobilization in Hybrid Media Systems" at the Department of Communication Studies and Media Research at the Ludwig-Maximilians-University of Munich. E-mail: Joerg.hassler@ifkw.lmu.de.

\section{How to cite}

Oschatz, C., Maurer, M. and Haßler, J. (2019). 'Learning from the news about the consequences of climate change: an amendment of the cognitive mediation model'. JCOM 18 (02), A07. https:/ / doi.org/10.22323/2.18020207. 